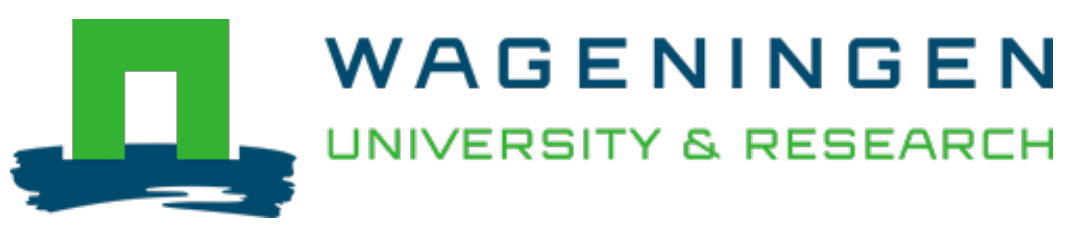

\title{
No effect of pyrolysis temperature and feedstock type on hydraulic properties of biochar and amended sandy soil
}

\section{Geoderma}

Wiersma, Wietse; Ploeg, Martine J.; Sauren, Ian J.M.H.; Stoof, Cathelijne R.

https://doi.org/10.1016/j.geoderma.2020.114209

This article is made publicly available in the institutional repository of Wageningen University and Research, under the terms of article $25 \mathrm{fa}$ of the Dutch Copyright Act, also known as the Amendment Taverne. This has been done with explicit consent by the author.

Article 25 fa states that the author of a short scientific work funded either wholly or partially by Dutch public funds is entitled to make that work publicly available for no consideration following a reasonable period of time after the work was first published, provided that clear reference is made to the source of the first publication of the work.

This publication is distributed under The Association of Universities in the Netherlands (VSNU) 'Article $25 \mathrm{fa}$ implementation' project. In this project research outputs of researchers employed by Dutch Universities that comply with the legal requirements of Article $25 \mathrm{fa}$ of the Dutch Copyright Act are distributed online and free of cost or other barriers in institutional repositories. Research outputs are distributed six months after their first online publication in the original published version and with proper attribution to the source of the original publication.

You are permitted to download and use the publication for personal purposes. All rights remain with the author(s) and / or copyright owner(s) of this work. Any use of the publication or parts of it other than authorised under article $25 \mathrm{fa}$ of the Dutch Copyright act is prohibited. Wageningen University \& Research and the author(s) of this publication shall not be held responsible or liable for any damages resulting from your (re)use of this publication.

For questions regarding the public availability of this article please contact openscience.library@wur.nl 


\title{
No effect of pyrolysis temperature and feedstock type on hydraulic properties of biochar and amended sandy soil
}

\author{
Wietse Wiersma $^{\mathrm{a}, \mathrm{b}}$, Martine J. van der Ploeg ${ }^{\mathrm{b}, \mathrm{c}}$, Ian J.M.H. Sauren ${ }^{\mathrm{a}, \mathrm{b}, 1}$, Cathelijne R. Stoof ${ }^{\mathrm{a}, *}$ \\ ${ }^{a}$ Soil Geography and Landscape Group, Wageningen University, P.O. Box 47, 6700 AA Wageningen, The Netherlands \\ ${ }^{\mathrm{b}}$ Soil Physics and Land Management Group, Wageningen University, P.O. Box 47, 6700 AA Wageningen, The Netherlands \\ ${ }^{\mathrm{c}}$ Hydrology and Quantitative Water Management Group, Wageningen University, P.O. Box 47, 6700 AA Wageningen, The Netherlands
}

\section{A R T I C L E I N F O}

Handling Editor: Yvan Capowiez

Keywords:

Biochar

Water retention

Saturated hydraulic conductivity

Hydrophobicity

Sandy soil

Soil amendment

\begin{abstract}
A B S T R A C T
Biochar has been lauded as a cure-all for improving water availability in soils. Yet the effect of pyrolysis temperature and feedstock type on biochar hydraulic properties and its subsequent effects on soils are not well known. We therefore systematically studied water retention, saturated hydraulic conductivity $\left(\mathrm{K}_{\mathrm{sat}}\right)$ and hydrophobicity of 12 standard biochars (six feedstocks and two pyrolysis temperatures) developed by the UK Biochar Research Centre. The hydraulic properties were determined for pure crushed biochar, as well as for a sandy soil amended with $10 \mathrm{t} \mathrm{ha}^{-1}$ biochar (assessed three times over a period of 15 months). For pure biochar, the effect of feedstock-temperature treatments on the water retention curve was negligible. Rice husk at a pyrolysis temperature of $700{ }^{\circ} \mathrm{C}$ had a significantly lower saturated water content, plant available water content and $\mathrm{K}_{\text {sat }}$ than all other biochar treatments. This can be attributed to its severe hydrophobicity: while all other treatments were non-hydrophobic and rice husk at $550{ }^{\circ} \mathrm{C}$ and Miscanthus straw at $550{ }^{\circ} \mathrm{C}$ were both strongly hydrophobic, rice husk at $700{ }^{\circ} \mathrm{C}$ was severely hydrophobic. Incorporation of the biochar into a sandy soil did not significantly influence soil water retention, saturated hydraulic conductivity and hydrophobicity. There were also no significant differences between the biochar treatments. These results indicate that except for rice husk at $700{ }^{\circ} \mathrm{C}$ the different biochar feedstock types and pyrolysis temperatures yield surprisingly similar material in terms of hydraulic characteristics. Improved soil hydrology should not be a main reason to apply biochar on sandy soils, but if biochar is applied differences in hydrophobicity should be considered.
\end{abstract}

\section{Introduction}

Biochar, the product of organic matter burned in an oxygen-limited environment, has been called a revolutionary soil improvement strategy to increase agricultural productivity, notably through improved soil hydrology and fertility (Lehmann and Joseph, 2009). Additionally, due to its long residence time in the soil, biochar serves as a potential carbon sink (Atkinson et al., 2010; Crombie et al., 2013). Biochar can be produced from a wide variety of feedstocks at a range of pyrolysis temperatures, and both factors influence the physio-chemical characteristics of a specific biochar type (Gray et al., 2014; Rutherford et al., 2012). Nevertheless, there is currently a lack of systematic understanding of the effects of feedstock type and pyrolysis temperature on the hydraulic properties of pure biochar and how both factors impact the hydraulic characteristics of a biochar-amended soil.

Little is known about the effect of pyrolysis temperature on pure biochar hydraulic properties, especially the saturated hydraulic conductivity $\left(\mathrm{K}_{\text {sat }}\right)$ and water retention characteristics. However, the hydrophobicity of pure biochar, which is likely to affect hydraulic conductivity and water retention capacity (Omondi et al., 2016), has been shown to decrease with increasing temperature in the range of 300-800 ${ }^{\circ} \mathrm{C}$ (Gray et al., 2014; Suliman et al., 2017; Zornoza et al., 2016). Because pyrolysis temperature controls combustion completeness and several physio-chemical properties such as specific surface area and carbon content (e.g. Jeong et al., 2016), it likely also influences biochar $\mathrm{K}_{\mathrm{sat}}$ and water retention. However, this link has not been established in literature. Similar to pure biochar, there is inconclusive evidence on the effect of pyrolysis temperature on the hydraulic properties of biochar-amended soil. Some studies found a stronger decrease in $\mathrm{K}_{\mathrm{sat}}$ and increase in water retention in a biochar-amended sandy-loamy soil when biochar was produced at higher temperature (Esmaeelnejad et al., 2016; Lei and Zhang, 2013). Furthermore,

\footnotetext{
* Corresponding author.

E-mail address: Cathelijne.Stoof@wur.nl (C.R. Stoof).

${ }^{1}$ Wageningen University Groups are past addresses.
} 
Omondi et al. (2016) showed in their review that for a variety of biochar feedstocks and soil textures high temperature $\left(>500{ }^{\circ} \mathrm{C}\right.$ ) biochar amendment significantly increased mean soil $\mathrm{K}_{\text {sat }}$ by $40 \%$ while amendment of $250-500{ }^{\circ} \mathrm{C}$ biochar had no effect. This increase in soil $\mathrm{K}_{\mathrm{sat}}$ with biochar production temperature has been attributed to an increase in pore volume and decrease in hydrophobicity (Kinney et al., 2012; Zimmerman, 2010). At the same time, Suliman et al. (2017) found no temperature dependency of a biochar-amended sandy soil.

Besides pyrolysis temperature the biochar feedstock type, or the original material that the biochar is derived from, is known to affect biochar hydraulic properties in several ways. Omondi et al. (2016) reported that in general biochars derived from crop residues have greater porosity and $\mathrm{K}_{\text {sat }}$ than wood-derived biochars, while Jeong et al. (2016) found that the range of the water holding capacity was significantly larger for rice husk biochar than for sugarcane residue biochar. Furthermore, feedstock type was found to influence biochar hydrophobicity (Cantrell et al., 2012; Cely et al., 2015). For example, Chintala et al. (2014) found that biochars derived from corn stover and switchgrass had a significantly higher hydrophobicity than biochar derived from ponderosa pine wood. However, other studies found no effect of feedstock type on hydrophobicity (Hale et al., 2015; Zornoza et al., 2016). Therefore, it seems likely that other factors, such as pyrolysis temperature, also have a strong influence on biochar hydraulic properties. The ambiguity about the effect of feedstock selection on pure biochar hydraulic properties agrees with that on the hydraulic properties of a biochar-amended soil. Some studies found a significant effect (Eibisch et al., 2015; Lei and Zhang, 2013; Novak et al., 2012), while others did not (Bayabil et al., 2015; Hardie et al., 2014; Ojeda et al., 2015). For example, Novak et al. (2012) found that switchgrass biochar amendment to silt loam to loamy sand soils resulted in a significantly higher water holding capacity compared to eight other biochar feedstock types. This effect was modestly linked to the lower soil bulk density upon biochar addition (Novak et al., 2012).

Understanding effects of feedstock type, pyrolysis temperature and time on biochar hydraulic properties is essential for identification of production conditions that are optimal for creating the most effective biochar for field use. Yet the efficacy of a biochar to achieve desired results when amended to soil is also strongly controlled by the properties of the receiving soil (Omondi et al., 2016) and the rate of biochar application (Laghari et al., 2016b). As a result, biochar has been found to increase soil water retention in some studies (e.g. Eibisch et al., 2015), while other studies have found no effect (Hardie et al., 2014; Herath et al., 2013). Regarding soil $\mathrm{K}_{\mathrm{sat}}$, biochar amendment has shown increases (e.g. Asai et al., 2009), decreases (e.g. Barnes et al., 2014) and no changes (Jeffery et al., 2015; Major et al., 2012). In terms of soil hydrophobicity, several authors found no changes after amendment of biochar produced from various feedstock types and pyrolysis temperatures to a sandy soil (Abel et al., 2013; Głąb et al., 2016), a sandyclay-loam (Baronti et al., 2014) and a silt loam (Herath et al., 2013). The efficacy of biochar to achieve desired soil hydraulic properties also changes over time due to environmental exposures such as temporal changes in temperature and water content, tillage practice, fertilization, porosity, root formation and changes in organic matter or microbes (Baronti et al., 2014; Lehmann and Joseph, 2009; Sorrenti et al., 2016). However, the effect of time on soil hydraulic properties after biochar amendment is rarely linear nor independent of feedstock type, pyrolysis temperature and soil texture (Brodowski et al., 2006; Nelissen et al., 2015; Verheijen et al., 2010). Altogether, time does not appear to have a strong influence on soil hydraulic properties, which is corroborated by studies which ran for several years (e.g. Hardie et al., 2014; Jeffery et al., 2015).

The objective of this study was to systematically assess the effect of pyrolysis temperature and feedstock type on the hydraulic properties of pure biochar in combination with the various biochar treatments being implemented as soil amendments in a sandy soil. We hypothesized that an increase in pyrolysis temperature would increase the saturated conductivity and water holding capacity, due to the decrease in hydrophobicity. We moreover hypothesized feedstock type to significantly affect pure biochar saturated conductivity, water holding capacity and hydrophobicity because of differences in the porosity of the original unburned material and the ash content of the burned material. Finally, we expected biochar amendment to improve the generally poor hydraulic properties (e.g. low water holding capacity) of a sandy soil, with temperature and feedstock effects on the pure biochar characteristics to remain apparent in the hydraulic characterization of the amended soil. We tested these hypotheses in a factorial experiment using the twelve standard biochars developed at the UK Biochar Research Centre (six feedstocks at two pyrolysis temperatures), that were tested for water retention capacity, hydraulic conductivity and hydrophobicity in pure form and during a 15 month field experiment.

\section{Methods}

\subsection{Experimental design}

The 12 standard biochars included six feedstocks: Miscanthus straw pellets (MSP), oil seed rape (OSR), rice husk (RH), sewage sludge (SS), soft wood pellets (SWP) and wheat straw pellets (WSP), which were all pyrolyzed at 550 and $700{ }^{\circ} \mathrm{C}$. Physical and chemical properties of these materials can be requested from the UK Biochar Research Centre 'Charchives' (https://www.biochar.ac.uk/charchive.php). Pure biochar samples were tested for water retention capacity, saturated hydraulic conductivity $\left(\mathrm{K}_{\mathrm{sat}}\right)$ and hydrophobicity in laboratory experiments. The effect of hydrophobicity on the saturated water retention of pure biochar was additionally assessed by comparison of saturation with water and with ethanol. Biochar other than rice husk was supplied in pelletform which makes it difficult to determine its hydraulic properties, as the laboratory methods require good contact between the porous medium and the measurement setup (water retention capacity), and assessment of a known volume of material (hydraulic conductivity, water retention). Therefore, to ensure adequate and uniform analysis, all biochars were manually crushed with a ceramic mortar in a pestle and sieved to $2 \mathrm{~mm}$.

The degree to which feedstock type and pyrolysis temperature effects hold when uncrushed biochar is amended to soil and breaks down during the first 15 months after amendment (two growing seasons) was tested in a field experiment on a sandy soil without tillage. Uncrushed biochar was used in agreement with common agronomic practices (e.g. Joseph et al., 2015). Topsoil $\mathrm{K}_{\text {sat }}$ and hydrophobicity were measured three times ( 1 week, 1 month and 15 months after amendment), and $0-5 \mathrm{~cm}$ soil water retention was determined at the end of the field experiment.

\subsection{Pure biochar analysis}

For the water retention experiments $100 \mathrm{~cm}^{3}$ rings (height $5.0 \mathrm{~cm}$, diameter $5.0 \mathrm{~cm}$ ) were lined with cheesecloth and manually filled with crushed biochar. To ensure reproducibility of sample filling, the rings were then softly tapped three times on the table and the remaining space gently filled to the rim. This procedure was assumed not to influence the variability of the bulk density between the biochar treatments. The average bulk density ranged from 0.17 to $0.54 \mathrm{~g} \mathrm{~cm}^{-3}$ (standard deviation 0.01-0.02 $\mathrm{g} \mathrm{cm}^{-3}$ ) depending on biochar feedstock and production temperature (Appendix 1). Biochar samples were slowly saturated from the bottom up until the biochar was visually wet at the top. For tensions between 0 and $9.8 \mathrm{kPa}$ a sandbox with movable water column (non-chlorinated tap water) was used ( $n=5$ per treatment). To get accurate air entry values, small steps in tension were used in the wet range of the retention curve: from 0 to $2 \mathrm{kPa}$ steps of $\sim 0.25 \mathrm{kPa}$ were used, followed by analysis at 2.5, 3.1, 4.0, 4.9, 6.4, 7.9 and $9.8 \mathrm{kPa}$. Separate biochar samples were prepared to measure water retention at 98 and $1554 \mathrm{kPa}$ using pressure plates $(\mathrm{n}=8$ per treatment). After each 
tension step the samples were weighed. When tensions of $9.8,98$ and $1554 \mathrm{kPa}$ were reached the samples were dried at $105^{\circ} \mathrm{C}$ for $24 \mathrm{~h}$ and weighed again. Using the sample volume, the difference in weight was used to calculate the volumetric moisture content at each tension. The sample volume of the pressure plate samples was calculated using the bulk density of the sandbox samples for each respective treatment.

Following Schwen et al. (2015), the potential saturated moisture content was determined by analysing 'water' retention capacity with $96 \%$ ethanol instead of non-chlorinated tap water $(n=5$ per treatment). To prevent contamination of the sandbox setups with ethanol, as well as adhere to safety regulations concerning the use of flammable liquids, we built dedicated ethanol sandbox setups in a fume hood. To accommodate for the smaller space of these new sandboxes, we constructed $3.5 \mathrm{~cm}^{3}$ sampling rings (height $1.65 \mathrm{~cm}$, diameter $1.65 \mathrm{~cm}$ ). Following Jarvis et al. (2008), we applied a correction factor of 1.25 to the depth of the hanging water column to correct for the density of ethanol relative to that of water. We attempted to characterize the entire retention curve with ethanol, but because of instant height equilibrium (i.e. our setup did not succeed in generating sufficient suction) the quality of the data at tensions below saturation was inadequate, hence only the saturated ethanol data are presented here. Additionally, the hydrophobicity was measured on crushed and sieved biochar $(n=5)$ by the water drop penetration time (WDPT) following Dekker \& Jungerius (1990).

To determine the water saturated hydraulic conductivity $\left(\mathrm{K}_{\mathrm{sat}}\right)$, uncompacted crushed biochar was put in $100 \mathrm{~cm}^{3}$ rings (height $5.0 \mathrm{~cm}$, diameter $5.0 \mathrm{~cm}$ ) lined with cheesecloth following the same procedure as for the water retention experiments, and slowly saturated from the bottom up with non-chlorinated tap water. Three replicates were run per treatment, except for the $550{ }^{\circ} \mathrm{C}$ rice husk biochar for which insufficient material only allowed for two replicates. The top of each sampling ring was extended with plastic tape, after which each ring was mounted on a tripod below an inverted 1 L flask filled with nonchlorinated tap water serving as a Mariotte reservoir. Initially water was released slowly until a constant head was achieved above the biochar sample. Subsequently the bottom outflow volume was read every $20 \mathrm{~s}$ in a 100 or $250 \mathrm{~mL}$ graduated cylinder (depending on the initial rate) until the rate became constant, which happened within 3 min for all runs. $\mathrm{K}_{\text {sat }}\left(\mathrm{cm} \mathrm{s}^{-1}\right)$ was calculated by applying Darcy's Law from the measured outflow rate, the height of the constant water head and the height of the biochar sample (Lei and Zhang, 2013).

\subsection{Biochar-amended soil analysis}

The field experiment was performed at Unifarm of Wageningen University and Research $\left(51^{\circ} 59^{\prime} 18.2^{\prime \prime} \mathrm{N}, 5^{\circ} 39^{\prime} 41.3^{\prime \prime} \mathrm{E}\right)$, north of Wageningen, the Netherlands. The soil is mapped as a mixed unit as "veldpodzol" (Hn21) and "beekeerdgrond" (pZg21) on fine (loamy) sand (Stiboka, 1975: map $40 \mathrm{~W}$ ). This directly translates into a 'veld' podzol and a 'beek' earth soil following De Bakker et al. (1989); in the WRB system (IUSS Working Group WRB, 2015), these soils resemble a wet Podzol and a Gleysol or Arenosol, the latter depending on at which depth the gley mottels start. The mean annual temperature of the region is $9.4{ }^{\circ} \mathrm{C}$ and the average annual precipitation $840 \mathrm{~mm}$ (Jeffery et al., 2015). Before the start of the field experiment, the soil was homogenized with a cultivator to a depth of $15 \mathrm{~cm}$. Across $\sim 30 \mathrm{~m}^{2}$ a grid was prepared of $0.5 \times 0.5 \mathrm{~m}$ plots separated by $0.2 \mathrm{~m}$ buffer strips. Biochar treatments and non-amended control plots were replicated three times and randomly assigned to the plots. Biochar was manually mixed into the top $10 \mathrm{~cm}$ of soil at an application rate of $10 \mathrm{t} \mathrm{ha}^{-1}$, in line with application rates reported in literature (Jeffery et al., 2015; Liu et al., 2016). Because of limited availability, the setup for rice husk biochar (both 550 and $700{ }^{\circ} \mathrm{C}$ ) was slightly different with $0.4 \times 0.4 \mathrm{~m}$ plots replicated twice. $\mathrm{K}_{\mathrm{sat}}$ and soil hydrophobicity were measured three times during a period of 15 months in 3-day campaigns, each within a one-week period (starting 2 May 2016, 9 Jun 2016 and 20 Aug 2017).
During this 15-month period the field was not managed except for standard farm irrigation scheduling, and periodic manual cutting and removal of naturally occurring weeds.

During each measurement day, the $\mathrm{K}_{\mathrm{sat}}$ was measured three times per plot for one set of replicates. A Mini Disk Portable Infiltrometer (METER Group Inc., 2018) was used with an applied suction of $2 \mathrm{~cm}$. The height of the water column was observed every $15 \mathrm{~s}$ until sufficient observations confirmed a constant infiltration rate, which usually happened between 1 and $2 \mathrm{~min}$. The infiltrometer hydraulic conductivity data are of unsaturated soil. These data were used to estimate the saturated hydraulic conductivity $\left(\mathrm{K}_{\mathrm{sat}}, \mathrm{cm} \mathrm{s}^{-1}\right)$, using the Van Genuchten factor for a sandy soil (1.73; METER Group Inc., 2018), which given the soil's particle size distribution $(86,10$ and $2 \%$ sand, silt and clay; Eurofins Agro, 2013) is reasonable.

Soil hydrophobicity was determined by the water drop penetration time (WDPT). Three drops were placed in a triangle around the area wetted by the $\mathrm{K}_{\mathrm{sat}}$ measurement and the time it took for the drops to infiltrate was observed. Following Dekker and Jungerius (1990) an infiltration time of $>5 \mathrm{~s}$ was classified as hydrophobic. To place the hydrophobicity measurements in context, the moisture content $\left(\mathrm{cm}^{3} \mathrm{~cm}^{-3}\right)$ of the top $5 \mathrm{~cm}$ of soil was measured four times per plot using a TRIME-TDR sensor (IMKO GmbH, Ettlingen, Germany), avoiding previously wetted soil.

Samples to determine the water retention of the biochar-amended soil were only taken at the end of the experiment (26 Aug 2017) due to the destructive character of the sampling. One sample was taken per plot in $100 \mathrm{~cm}^{3}$ rings (height $5.0 \mathrm{~cm}$, diameter $5.0 \mathrm{~cm}$ ), yielding three replicates except for the rice husk treatments for which there were two replicates. Samples were saturated from the bottom up, placed on a sand box, and weighed after each tension step of $10 \mathrm{kPa}$ in the range 0-100 $\mathrm{kPa}$. The samples were subsequently placed in pressure plates and weighed after 100 and $1500 \mathrm{kPa}$ were reached. Volumetric moisture content was calculated using the procedure described above for the pure biochar.

\subsection{Statistical analysis}

From the water retention data of both pure biochar and biocharamended soil the plant available water content (PAW) was calculated as the difference between the moisture content at field capacity ( $\mathrm{pF} 2$; $\mathrm{h}=-10 \mathrm{kPa}$ ) and at permanent wilting point ( $\mathrm{pF} 4.2 ; \mathrm{h}=-1500 \mathrm{kPa})$. For pure biochar the median water content at $\mathrm{pF} 4.2$ was subtracted from the value at $\mathrm{pF} 2$ to calculate PAW per treatment because separate samples were used for the determination of the moisture content at field capacity and at wilting point. The air entry pF-value (AEV) was calculated as the intersection between the minimum slope of the water retention curve and the vertical line from the saturated water content $\left(\theta_{\mathrm{s}}\right)$.

All statistical analyses were performed using $R$ ( $R$ Core Team, 2013). One-way Analysis of Variance (ANOVA) was used to test the significance of the effects of the 12 feedstock-temperature treatments on the $\theta_{\mathrm{s}}$, PAW, AEV and $\mathrm{K}_{\mathrm{sat}}$ of both pure biochar and the biocharamended soil (for which the control was added as the 13th treatment). Additionally, the effect of time on the biochar-amended soil $\mathrm{K}_{\text {sat }}$ was studied with one-way ANOVA. Differences between the actual and potential saturated water content $\left(\theta_{s}\right)$ were examined with a two-way ANOVA including liquid type (water and 96\% ethanol, respectively) and biochar treatment as factors. For factors for which ANOVA suggested significant results, differences between group means were identified with Tukey honest significant difference (HSD) tests. Since the pure biochar AEV data was not normally distributed (Shapiro-Wilk test $\mathrm{p}<0.05$ ) even after transformation, the Mann-Whitney $U$ test was applied (Mann and Whitney, 1947).

The one-sided two sample Kolmogorov-Smirnov test was used to quantify whether the water retention data were similar (null hypothesis) or different (null hypothesis rejected) for different treatments of 


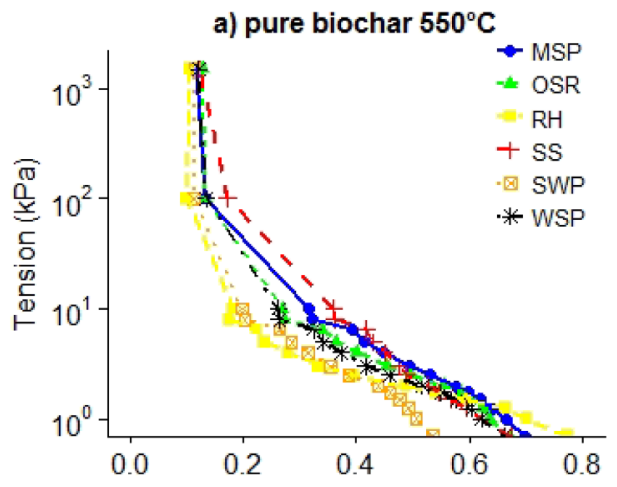

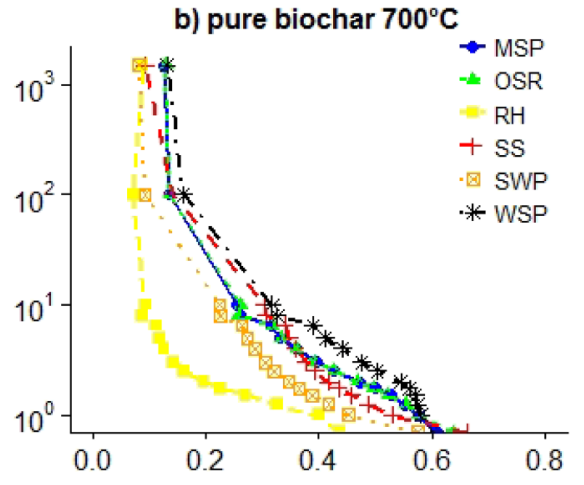

Fig. 1. Water retention curves of pure biochar (upper) and biochar-amended soil (lower) for the $550{ }^{\circ} \mathrm{C}$ (left) and $700{ }^{\circ} \mathrm{C}$ treatments (right). Curves are constructed with average water content $(\mathrm{n}=5)$ in $\mathrm{cm}^{3} \mathrm{~cm}^{-3}$ and tension in $\mathrm{kPa}$ and are given per feedstock type: Miscanthus straw pellets (MSP), oil seed rape (OSR), rice husk (RH), sewage sludge (SS), soft wood pellets (SWP), wheat straw pellets (WSP) and unamended soil (Control). Lines are drawn for ease of interpretation.

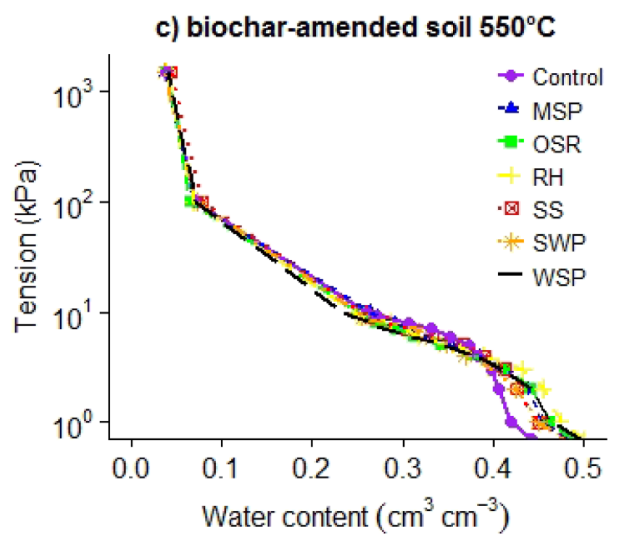

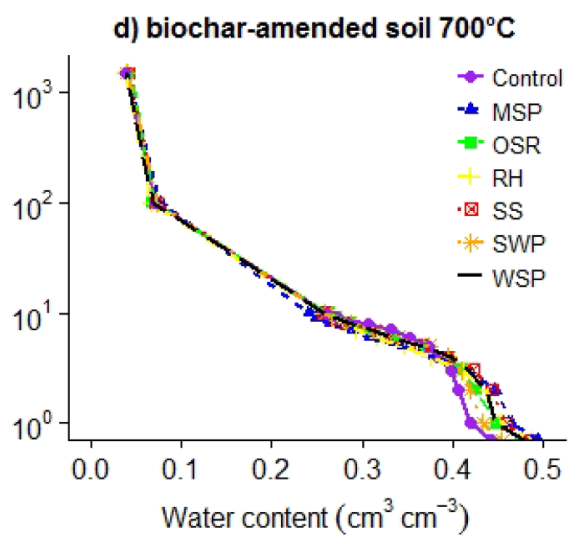

pure biochar and the biochar-amended soil (Gail and Green, 1976). Measured water retention data were accumulated and scaled with $\theta_{\mathrm{s}}$ as the maximum value. Obtained differences were screened against the critical distance at different significant levels $(\alpha)$ above which the null hypothesis would be rejected.

\section{Results}

\subsection{Pure biochar}

\subsubsection{Water retention}

The water retention curves of pure biochar indicate that soft wood pellets $550{ }^{\circ} \mathrm{C}$ biochar had a lower water content compared to the other feedstock types at tensions $<10 \mathrm{kPa}$. Above this tension the curves seemed to converge (Fig. 1). For the $700{ }^{\circ} \mathrm{C}$ treatments rice husk biochar had a lower water content compared to all other feedstock types at nearly all tensions. Analysis of variance revealed a significant treatment effect ( $\mathrm{p}<0.001$ ) on the saturated water content $\left(\theta_{\mathrm{s}}\right)$ of pure biochar. The lowest $\theta_{s}$ was found for rice husk $700{ }^{\circ} \mathrm{C}$ biochar (average $0.44 \mathrm{~cm}^{3} \mathrm{~cm}^{-3}$ ), while rice husk $550{ }^{\circ} \mathrm{C}$ had the highest $\theta_{\mathrm{s}}$ (average $0.77 \mathrm{~cm}^{-3}$ ). Additionally, the higher pyrolysis temperature had a significantly lower $\theta_{\mathrm{s}}$ for Miscanthus straw pellets and rice husk, while for the other feedstock types there was no significant effect of temperature (Fig. 2a). The PAW was also significantly influenced by the biochar feedstock-temperature treatments $(\mathrm{p}<0.001)$. Rice husk had a significantly lower PAW than all other treatments (Fig. 2b), and rice husk $700{ }^{\circ} \mathrm{C}$ had on average no plant available water. Furthermore, for rice husk and Miscanthus straw the higher temperature biochar had a significantly lower PAW, while for wheat straw the reverse was found (Fig. 2b). Finally, the Mann-Whitney $U$ test revealed that the air entry value (AEV) of rice husk $700{ }^{\circ} \mathrm{C}$ was significantly lower than that of Miscanthus straw pellets biochar at both temperatures, as well as soft wood $\left(550{ }^{\circ} \mathrm{C}\right)$ and wheat straw pellets $\left(700{ }^{\circ} \mathrm{C}\right.$ ) biochar (Fig. $2 \mathrm{c}$ ).

The Kolmogorov-Smirnov maximum distances in Table 1 illustrate differences between the water retention curves of different biochar feedstock types and pyrolysis temperatures. The maximum distance was not significantly affected by feedstock or temperature at $\mathrm{p}<0.10$, except for rice husk $700{ }^{\circ} \mathrm{C}$ biochar, which was significantly different from wheat straw pellets $700{ }^{\circ} \mathrm{C}$ (at $\alpha=0.05$ ) and Miscanthus straw pellets $550{ }^{\circ} \mathrm{C}$ biochar (at $\alpha=0.10$ ).

\subsubsection{Saturated hydraulic conductivity}

The $\mathrm{K}_{\mathrm{sat}}$ of pure biochar differed significantly per feedstock-temperature treatment $(\mathrm{p}=0.002)$. Soft wood $550{ }^{\circ} \mathrm{C}$ biochar with on average $61.2 \mathrm{~cm} \mathrm{~h}^{-1}$ (range $32-102 \mathrm{~cm} \mathrm{~h}^{-1}$ ) had the highest $\mathrm{K}_{\text {sat }}$, which was only significantly higher than oil seed rape, rice husk, sewage sludge and wheat straw pellets all pyrolyzed at $700{ }^{\circ} \mathrm{C}$ (Fig. 3a). Rice husk $700{ }^{\circ} \mathrm{C}$ biochar had the lowest average $\mathrm{K}_{\text {sat }}$ (average $9.0 \mathrm{~cm} \mathrm{~h}^{-1}$; range $3.8-15 \mathrm{~cm} \mathrm{~h}^{-1}$ ), which was significantly lower than all other treatments (Fig. 3a). Except for rice husk, there were no significant differences between $K_{\text {sat }}$ values of biochars derived from the same feedstock but created at different temperatures.

\subsubsection{Actual versus potential saturated water content}

The pure biochar actual and potential saturated water content $\left(\theta_{\mathrm{s}}\right)$ were determined with liquid retention experiments with tap water and ethanol, respectively. There was a significant interaction between treatment and liquid type $(\mathrm{p}<0.001)$. In general, the potential $\theta_{\mathrm{s}}$ was significantly higher than the actual $\theta_{\mathrm{s}}$ for all biochar feedstocks except Miscanthus straw, rice husk and sewage sludge at $550{ }^{\circ} \mathrm{C}$ and soft wood at $700{ }^{\circ} \mathrm{C}$ (Fig. 4). Rice husk biochar had a significantly lower actual $\theta_{\mathrm{s}}$ at $700{ }^{\circ} \mathrm{C}$ than at $550{ }^{\circ} \mathrm{C}$, which in turn was not significantly different from the potential $\theta_{\mathrm{s}}$ of rice husk at both temperatures. The sewage sludge $700{ }^{\circ} \mathrm{C}$ treatment had a significantly higher potential $\theta_{\mathrm{s}}$ than the $550^{\circ} \mathrm{C}$ biochar, which in turn did not differ significantly from the actual $\theta_{s}$ of sewage sludge at both temperatures.

The hydrophobicity data revealed that the rice husk treatments were strongly (WDPT 60-600 s) and severely hydrophobic (WDPT 

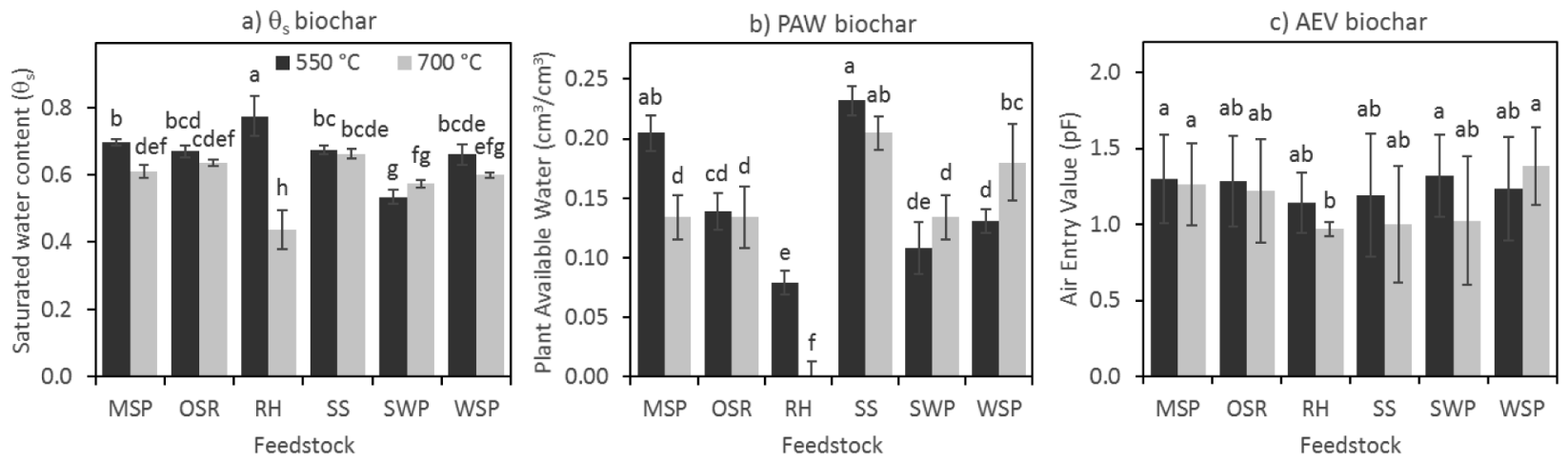

Fig. 2. Pure biochar average saturated water content $\left(\theta_{s}\right)$, plant available water content $(P A W)$ and air entry value (AEV) $(n=5)$. Error bar represents one standard deviation. Treatments not sharing the same letter are significantly different at $\mathrm{p}<0.05$. Abbreviations: Miscanthus straw pellets (MSP), oil seed rape (OSR), rice husk (RH), sewage sludge (SS), soft wood pellets (SWP) and wheat straw pellets (WSP).

600-3600 s) when pyrolyzed at $550^{\circ} \mathrm{C}$ and $700{ }^{\circ} \mathrm{C}$, respectively (Fig. 4). Miscanthus straw $550{ }^{\circ} \mathrm{C}$ was also strongly hydrophobic. All other treatments were non-hydrophobic (WDPT $<5$ s).

\subsection{Biochar-amended soil}

\subsubsection{Water retention}

The water retention characteristics of the biochar-amended soil were similar across treatments (Fig. 1c, d). This was confirmed by the Kolmogorov-Smirnov maximum distances, which indicated that there was no significant effect of feedstock and temperature (Table 1). Analysis of the significant treatment effect on the saturated water content of the soil $(\mathrm{p}=0.018)$ revealed that rice husk $550{ }^{\circ} \mathrm{C}$, wheat straw $550{ }^{\circ} \mathrm{C}$ and Miscanthus straw $700{ }^{\circ} \mathrm{C}$ had a significantly higher $\theta_{\mathrm{s}}$ than the unamended control soil (average 0,50, 0.50, $0.49 \mathrm{~cm}^{3} \mathrm{~cm}^{-3}$ vs $0.44 \mathrm{~cm}^{3} \mathrm{~cm}^{-3}$, respectively; Fig. 5a). There was no significant effect of feedstock-temperature treatment on PAW (p = 0.935) and AEV $(\mathrm{p}=0.615)$ (Fig. 5b, c).

\subsubsection{Saturated hydraulic conductivity}

In the biochar-amended soil experiment biochar treatment did not affect $\mathrm{K}_{\mathrm{sat}}(\mathrm{p}=0.644$, Fig. $3 \mathrm{~b})$. However, the effect of time was significant irrespective of the biochar treatment $(p<0.001)$ : the highest average soil $\mathrm{K}_{\mathrm{sat}}$ was found in after 1 month $(20 \pm$ one standard deviation of $\left.9 \mathrm{~cm} \mathrm{~h}^{-1}\right)$, followed by 1 week $\left(12 \pm 5 \mathrm{~cm} \mathrm{~h}^{-1}\right)$ and 15 months $\left(7 \pm 3 \mathrm{~cm} \mathrm{~h}^{-1}\right)$. The topsoil average moisture content \pm one standard deviation (in $\mathrm{cm}^{3} \mathrm{~cm}^{-3}$ ) during these campaigns was $0.06 \pm 0.03,0.001 \pm 0.006$ and $0.02 \pm 0.03$, respectively. Finally, the biochar-amended soil was non-hydrophobic (WDPT $<5$ s) for all treatments irrespective of time.

\section{Discussion}

\subsection{Hydraulic properties of pure biochar}

We hypothesized that the hydraulic properties of pure biochar would be affected by the biochar treatment, since it has been shown that feedstock selection and pyrolysis temperature govern the physiochemical properties of biochar, such as the formation of pyrogenic nanopores and the presence of hydrophobic surfaces (Gray et al., 2014; Kinney et al., 2012). In contrast to this hypothesis, we found few and inconclusive effects of feedstock-temperature treatments on pure

Table 1

Pure biochar (dark-grey background) and biochar-amended soil (light-grey background) maximum distance (D) between scaled water retention data for different feedstock (FS) and temperature (T) treatments for one-sided two-sample Kolmogorov-Smirnov test. Abbreviations: Miscanthus straw pellets (MSP), oil seed rape (OSR), rice husk (RH), sewage sludge (SS), soft wood pellets (SWP), wheat straw pellets (WSP) and unamended soil (Control). Bold values are significant.

\begin{tabular}{|l|l|l|l|l|l|l|l|l|l|l|l|l|l|}
\hline FS-T & $\begin{array}{l}\text { WSP- } \\
550\end{array}$ & $\begin{array}{l}\text { WSP- } \\
700\end{array}$ & $\begin{array}{l}\text { SWP- } \\
550\end{array}$ & $\begin{array}{l}\text { SWP- } \\
700\end{array}$ & $\begin{array}{l}\text { SS- } \\
550\end{array}$ & $\begin{array}{l}\text { SS- } \\
700\end{array}$ & $\begin{array}{l}\text { RH- } \\
550\end{array}$ & $\begin{array}{l}\text { RH- } \\
700\end{array}$ & $\begin{array}{l}\text { MSP- } \\
550\end{array}$ & $\begin{array}{l}\text { MSP- } \\
700\end{array}$ & $\begin{array}{l}\text { OSR- } \\
550\end{array}$ & $\begin{array}{l}\text { OSR- } \\
700\end{array}$ & $\begin{array}{l}\text { Con- } \\
\text { trol }\end{array}$ \\
\hline $\begin{array}{l}\text { WSP- } \\
550\end{array}$ & 0.086 & 0.094 & 0.128 & 0.077 & 0.077 & 0.048 & 0.064 & 0.077 & 0.027 & 0.048 & 0.090 & 0.189 \\
\hline $\begin{array}{l}\text { WSP- } \\
700\end{array}$ & 0.170 & & 0.059 & 0.048 & 0.023 & 0.024 & 0.065 & 0.062 & 0.043 & 0.076 & 0.069 & 0.019 & 0.103 \\
\hline $\begin{array}{l}\text { SWP- } \\
550\end{array}$ & 0.039 & 0.164 & & 0.095 & 0.042 & 0.043 & 0.046 & 0.051 & 0.030 & 0.067 & 0.049 & 0.053 & 0.117 \\
\hline $\begin{array}{l}\text { SWP- } \\
700\end{array}$ & 0.199 & 0.304 & 0.225 & & 0.056 & 0.069 & 0.112 & 0.108 & 0.090 & 0.123 & 0.115 & 0.047 & 0.061 \\
\hline $\begin{array}{l}\text { SS- } \\
550\end{array}$ & 0.137 & 0.128 & 0.164 & 0.177 & & 0.028 & 0.057 & 0.052 & 0.034 & 0.071 & 0.059 & 0.021 & 0.112 \\
\hline $\begin{array}{l}\text { SS- } \\
700\end{array}$ & 0.182 & 0.278 & 0.204 & 0.069 & 0.153 & & 0.046 & 0.044 & 0.021 & 0.061 & 0.047 & 0.023 & 0.114 \\
\hline $\begin{array}{l}\text { RH- } \\
550\end{array}$ & 0.210 & 0.377 & 0.232 & 0.171 & 0.331 & 0.235 & & 0.047 & 0.059 & 0.041 & 0.031 & 0.069 & 0.160 \\
\hline $\begin{array}{l}\text { RH- } \\
700\end{array}$ & 0.332 & 0.467 & 0.371 & 0.211 & 0.379 & 0.259 & 0.184 & & 0.032 & 0.047 & 0.019 & 0.061 & 0.149 \\
\hline $\begin{array}{l}\text { MSP- } \\
550\end{array}$ & 0.077 & 0.092 & 0.084 & 0.223 & 0.080 & 0.202 & 0.287 & 0.391 & & 0.067 & 0.045 & 0.043 & 0.120 \\
\hline $\begin{array}{l}\text { MSP- } \\
700\end{array}$ & 0.030 & 0.147 & 0.050 & 0.190 & 0.115 & 0.174 & 0.236 & 0.326 & 0.065 & & 0.031 & 0.084 & 0.174 \\
\hline $\begin{array}{l}\text { OSR- } \\
550\end{array}$ & 0.049 & 0.141 & 0.033 & 0.237 & 0.131 & 0.216 & 0.247 & 0.379 & 0.056 & 0.055 & & 0.069 & 0.156 \\
\hline $\begin{array}{l}\text { OSR- } \\
700\end{array}$ & 0.052 & 0.175 & 0.085 & 0.147 & 0.131 & 0.136 & 0.217 & 0.300 & 0.090 & 0.044 & 0.039 & & 0.099 \\
\hline
\end{tabular}



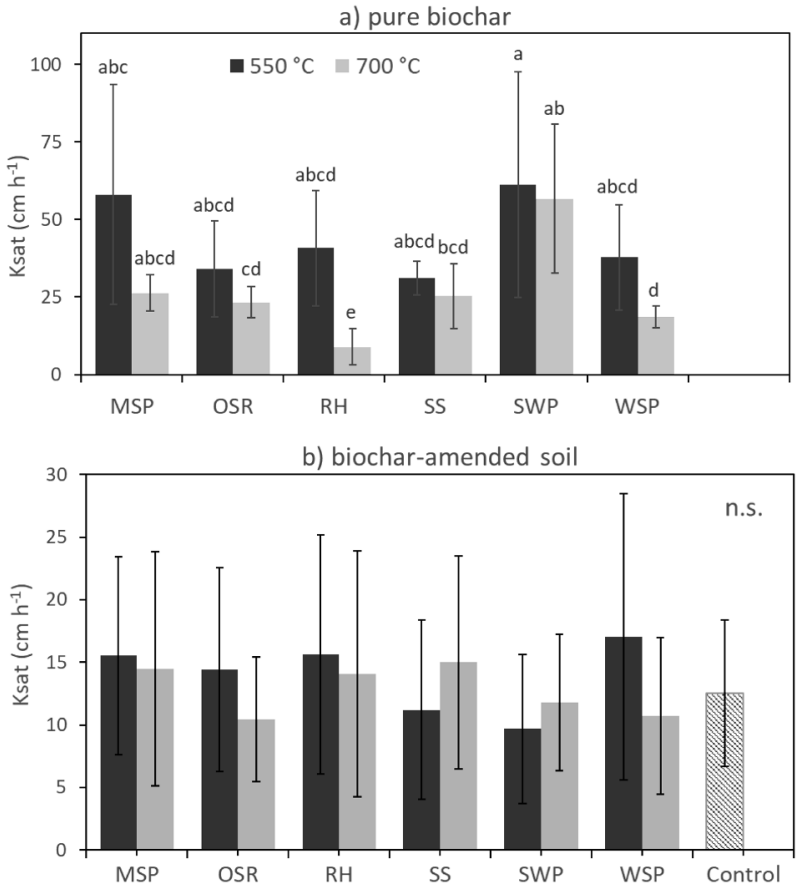

Fig. 3. Saturated hydraulic conductivity $\left(\mathrm{K}_{\mathrm{sat}}\right)$ of pure biochar (a) and biocharamended soil (b). Error bar represents one standard deviation. For pure biochar temperature treatments $n=3\left(n=2\right.$ for $\left.\mathrm{RH} 550{ }^{\circ} \mathrm{C}\right)$. For biochar-amended soil $\mathrm{n}=27$ (for $\mathrm{RH}$ at both temperatures $\mathrm{n}=18$ ). At $\mathrm{p}<0.05$ treatments are significantly different when not sharing the same letter; biochar-amended soil treatments were not significantly different (n.s.). Note the different range of $\mathrm{K}_{\mathrm{sat}}$ on the y-axis between plots A and B. Abbreviations: Miscanthus straw pellets (MSP), oil seed rape (OSR), rice husk (RH), sewage sludge (SS), soft wood pellets (SWP), wheat straw pellets (WSP) and unamended soil (Control).

biochar saturated water content $\left(\theta_{s}\right)$, plant available water content (PAW) and air entry value (AEV) (Fig. 2). The significant decrease in $\theta_{\mathrm{s}}$ and thus total porosity with temperature observed for Miscanthus straw and rice husk biochar (Fig. 2a) was reflected in a decrease in PAW (Fig. 2b). The decrease in $\theta_{\mathrm{s}}$ with temperature is in apparent disagreement with earlier studies in which the saturated water content of sugarcane and rice crop residue biochar increased with temperature (Jeong et al., 2016). This was attributed to the increase in surface area and the formation of pores resulting from the volatilization of organic compounds (Downie et al., 2009; Jeong et al., 2016). This different behaviour may be explained by the increase in hydrophobicity with temperature for Miscanthus straw and rice husk biochar (Fig. 4), which could have caused the lower $\theta_{s}$. The increase in hydrophobicity may have outweighed the structural effects of increased surface area and porosity.

Besides temperature, feedstock selection has also been shown to affect hydraulic properties, for example through differences in pore size distribution (Omondi et al., 2016). In this study, we found that for rice husk the PAW (at both temperatures) and $\theta_{s}$ (at $700{ }^{\circ} \mathrm{C}$ ) were significantly lower than for all other feedstock types (Fig. 2). This is most likely due to the high hydrophobicity of rice husk compared to all other non-hydrophobic treatments (Fig. 4). Furthermore, these differences between rice husk and the other feedstock types could be due to differences in particle size of the biochars but unfortunately no data is available to verify this. In contrast to rice husk, sewage sludge irrespective of temperature had a significantly higher PAW compared to all other treatments, except Miscanthus straw $550{ }^{\circ} \mathrm{C}$ and wheat straw $700{ }^{\circ} \mathrm{C}$ biochar (Fig. 2b). This may be attributed to the high residual ash content, which has been shown to increase water content at field capacity ( $-10 \mathrm{kPa}$; Yargicoglu et al., 2015), and is therefore also likely to increase plant available water. For most biochars the ash content was $<24 \%$ (UK Biochar Research Centre). For sewage sludge biochar it was $59 \%$ and $62 \%$ for 550 and $700{ }^{\circ} \mathrm{C}$, respectively. Since rice husk also had a relatively high ash content of $48-54 \%$, its low PAW is likely due to the dominance of the effect of hydrophobicity over the effect of the high ash content.

We found that the $\mathrm{K}_{\text {sat }}$ of pure rice husk $700{ }^{\circ} \mathrm{C}$ biochar was significantly lower compared to all other treatments (Fig. 3b). To which degree this can be explained by differences in particle size, as observed by (Yargicoglu et al., 2015) needs to be assessed. Additionally, the temperature effect may be attributed to differences in hydrophobicity, since rice husk $700{ }^{\circ} \mathrm{C}$ was more hydrophobic than $550{ }^{\circ} \mathrm{C}$ (severely and strongly hydrophobic, respectively, Fig. 4). This is corroborated by the water and ethanol retention experiments, for which rice husk $700{ }^{\circ} \mathrm{C}$ stood out as it was the only treatment that had significantly different actual and potential saturated water contents (Fig. 4). We are unable to

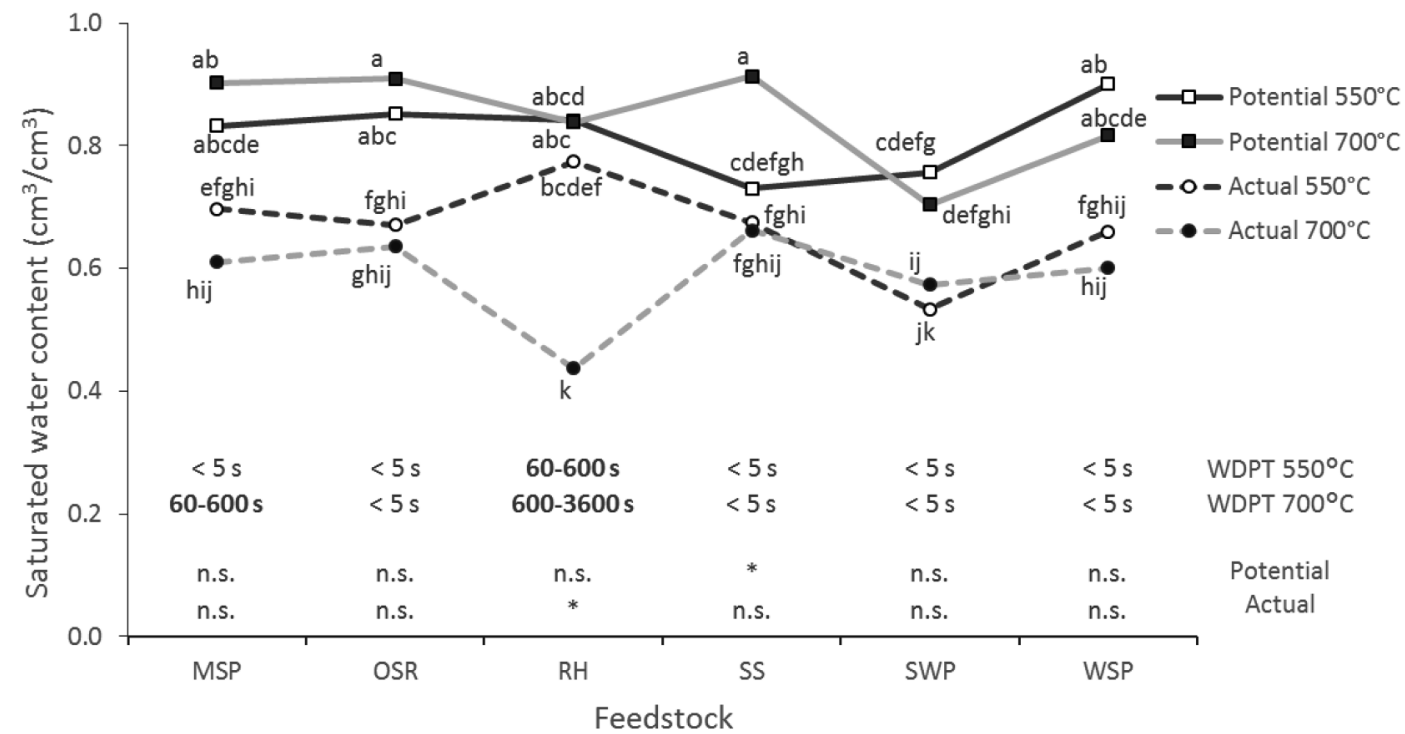

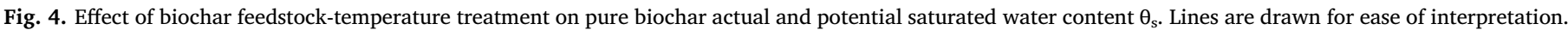

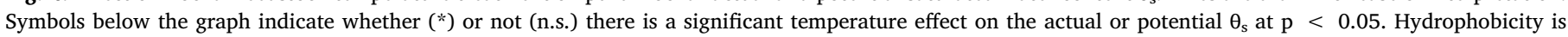

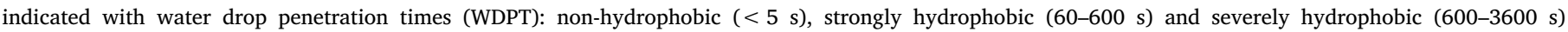

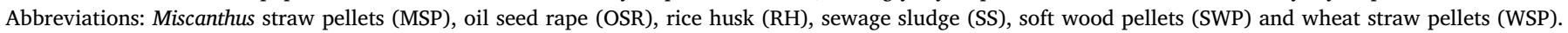



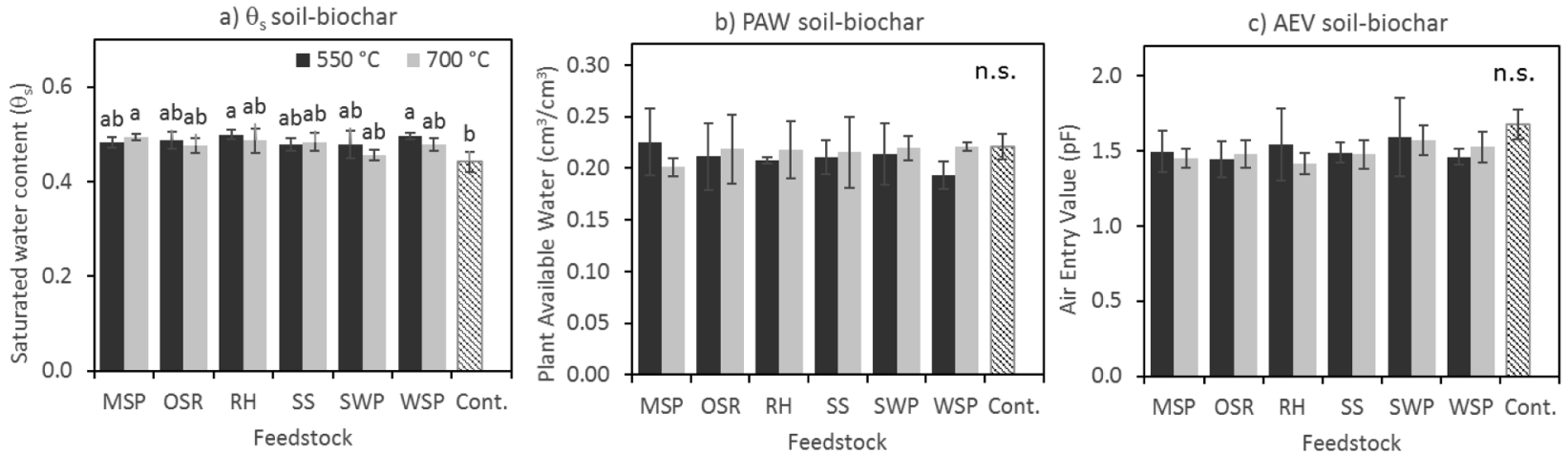

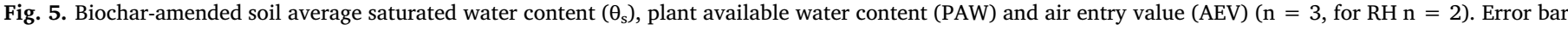

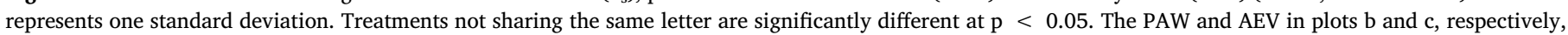

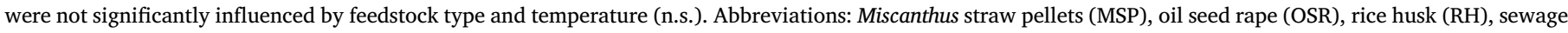
sludge (SS), soft wood pellets (SWP), wheat straw pellets (WSP) and unamended soil (Control).

explain why the hydrophobicity was higher for the 700 than the $550{ }^{\circ} \mathrm{C}$ treatment for the rice husk and Miscanthus straw biochars. Biochar literature (e.g. Gray et al., 2014), as well as studies on fire effects on soils (DeBano, 2000; Doerr et al., 2000), find a decrease in hydrophobicity with temperature. In soils subject to high (fire) temperatures, $350{ }^{\circ} \mathrm{C}$ is considered the temperature above which hydrophobicity is eliminated (DeBano, 2000), which makes the strongly hydrophobic rice husk biochar produced at $700{ }^{\circ} \mathrm{C}$ interesting. While it has been suggested that higher pyrolysis temperature would lead to higher hydrophobicity, due to the decrease in oxygen to carbon ratios indicating aromatic compounds (Cantrell et al., 2012), this has not been verified with experimental data. The similarity in $\mathrm{K}_{\text {sat }}$ and hydrophobicity between the treatments other than rice husk may be explained by the similar hydrophobicity of the biochars as shown by Chintala et al. (2014) for corn stover, switchgrass and pine wood biochar. Additionally, Zornoza et al. (2016) showed that biochars from several feedstock types lost the labile aliphatic compounds before $500{ }^{\circ} \mathrm{C}$, rendering them non-hydrophobic (Fig. 4). In conclusion, although hydrophobicity explains the low $\mathrm{K}_{\text {sat }}$, $\theta_{s}$ and PAW of rice husk biochar produced at $700{ }^{\circ} \mathrm{C}$, it remains unclear what caused differences between feedstock types and temperature treatments regarding these hydraulic properties (Fig. 2; Fig. 3a).

\subsection{Hydraulic properties of biochar-amended soil}

We found no significant effect of biochar amendment on soil water retention, PAW, AEV and $\mathrm{K}_{\mathrm{sat}}$. This absence of an effect agrees with previous studies (Hardie et al., 2014; Herath et al., 2013; Jeffery et al., 2015; Mollinedo et al., 2015) and may be attributed the biochar application rate, soil texture and breakdown period.

The biochar application rate of $10 \mathrm{t} \mathrm{ha}^{-1}$ used in this study is agronomically realistic, but likely too low to significantly affect soil hydraulic properties. In general, it has been shown that the effect of biochar on for example the soil saturated hydraulic conductivity increases with increasing application rates (De Melo Carvalho et al., 2014; Dokoohaki et al., 2017; Madari et al., 2017). However, these studies often use application rates that do not correspond to feasible agronomic practices. For example, Githinji (2014) found in a laboratory experiment that $\mathrm{K}_{\mathrm{sat}}$ linearly decreased with biochar application rate ${ }^{2}$ ( $>300 \mathrm{tha}^{-1}$ ) in a loamy sand soil. A similar soil was amended with $47 \mathrm{t} \mathrm{ha}^{-1}$ by Hardie et al. (2014) and $133 \mathrm{t} \mathrm{ha}^{-1}$ by Barnes et al. (2014). However, only Barnes et al. (2014) found a significant decrease in $\mathrm{K}_{\text {sat }}$. Therefore, although Laghari et al. (2016b) concluded that the application rate should be $>1 \%$ by weight or $>20 \mathrm{t} \mathrm{ha}^{-1}$ for a

\footnotetext{
${ }^{2}$ Githinji (2014) started with a mixing ratio of biochar with soil of $25 \% \mathrm{v} / \mathrm{v}$. The bulk density of the unamended soil was $1.33 \mathrm{~g} \mathrm{~cm}^{-3}$. In the top $10 \mathrm{~cm}$ of soil this yields $332.5 \mathrm{t}^{\text {biochar }} \mathrm{ha}^{-1}$.
}

significant increase in the soil water holding capacity to occur, we speculate that for a sandy soil the rate should be in the order of $100 \mathrm{t} \mathrm{ha}^{-1}$. Nonetheless, an application rate of this magnitude might not be socially and economically realistic (Joseph et al., 2015). Additionally, soil type is a major controlling factor for the effect of biochar on soil hydraulic properties (e.g. Omondi et al., 2016), because of differing structural and chemical properties due to the organic matter content, the presence of inorganic compounds and the nature of the reactive surfaces (Bayabil et al., 2015; Dexter, 1988; Herath et al., 2013). Overall, $10 \mathrm{tha}^{-1}$ is realistic but clearly too little to significantly change the hydraulic properties of a sandy soil (Jeffery et al., 2015).

The low application rate used in the current study does not necessarily prevent the soil from becoming hydrophobic upon biochar addition. Steenhuis et al. (2005) demonstrated that already a few hydrophobic grains (5.5\%) could prevent water entry into the soil. Although the application rate in the present study was between 1 and $2 \%$ (assuming a bulk density of 1 and $0.5 \mathrm{~g} \mathrm{~cm}^{-3}$, respectively), soil hydrophobicity could have been affected at the pore scale. Nevertheless, although small differences in WDPT values were indeed observed in the field, all treatments remained non-hydrophobic (WDPT $<5$ s) throughout the experiment, regardless of differences in pure biochar hydrophobicity (Fig. 4). These results are in agreement with some studies (e.g. Abel et al., 2013) but in contrast to Kinney et al. (2012), who observed that varying pure biochar hydrophobicity resulted in varying hydrophobicity of biochar-amended clay soil. However, these effects occurred mainly at the highest application rate $(7 \%$ of soil weight) and the measurements had a high variability, which was attributed to whether drops of the WDPT method fell on biochar or sand particles (Kinney et al., 2012). Hence, some drops may have reflected background soil whereas others reflected the biochar-amended soil. This suggests that the application rate in the present study was too low for an effect on hydrophobicity, since small-scale effects of biochar on soil hydrophobicity as expected based on Steenhuis et al. (2005) would have been captured in a high WDPT variability, similar to Kinney et al. (2012).

The application rate and the intrinsic variability of the soil hydraulic properties in the current study (notably the $\mathrm{K}_{\mathrm{sat}}$ as illustrated by the standard deviation of the unamended control soil in Fig. 3b), presumably also disguised small differences between the biochar treatments regarding the $\theta_{s}$, PAW, AEV or $\mathrm{K}_{\text {sat }}$ (Figs. 3 and 5). It seems realistic to expect that at higher dosages of biochar, effects of feedstock selection and pyrolysis temperature occur (Omondi et al., 2016), because of the influence of these production factors on the formation of pyrogenic nanopores, total surface area and acidic functional groups linked to hydrophobicity (Herath et al., 2013; Lehmann and Joseph, 2009; Zimmerman, 2010).

Finally, we found a significant effect of time on the soil $\mathrm{K}_{\text {sat }}$, 
irrespective of the biochar treatment. The significantly lower $\mathrm{K}_{\text {sat }}$ after one week compared to one month might be due to the recent mixing of the biochar (within four days of the week one measurements), although it was not possible to substantiate this. The $\mathrm{K}_{\mathrm{sat}}$ after 15 months was significantly lower than after one month (Section 3.2.2). Although no specific studies exist, it could be hypothesized that temporal changes in physio-chemical properties of the biochar-amended soil influence soil hydraulic properties (Brodowski et al., 2006; Nelissen et al., 2015; Verheijen et al., 2010). For example, Herath et al. (2013) found that the soil water content increased over time because the ash was diluted and removed from the biochar particles, thus increasing the total available pore space of the soil. Hence, the $\mathrm{K}_{\mathrm{sat}}$ in the present study may have decreased due to the breakdown of biochar over time. However, the $K_{\text {sat }}$ of the biochar-amended soil was not significantly different from the unamended soil neither after 1 month nor after 15 months $(\mathrm{p}=0.59$ and $\mathrm{p}=0.77$, respectively; data not shown). Therefore, it is unlikely that the decrease in $\mathrm{K}_{\mathrm{sat}}$ is due to biochar breakdown. This is in apparent agreement with other studies which ran for periods up to five years and reported no significant effects of biochar on soil hydraulic properties (Jeffery et al., 2015; Madari et al., 2017).

\section{Conclusions}

Although biochar is often labelled as a revolutionary soil improvement strategy (Jeffery et al., 2015), scientific evidence is equivocal. We systematically analysed effects of pyrolysis temperature and feedstock type on hydraulic properties of pure biochar and a biochar-amended sandy soil. In general, the twelve biochar types studied here were similar in terms of water retention curve, saturated water content $\left(\theta_{s}\right)$, plant available water (PAW), air entry value (AEV) and saturated hydraulic conductivity $\left(\mathrm{K}_{\text {sat }}\right)$. Rice husk $700{ }^{\circ} \mathrm{C}$ had a significantly lower $\theta_{\mathrm{s}}$, PAW and $\mathrm{K}_{\mathrm{sat}}$ compared to all other biochar treatments, which was attributed to its severe hydrophobicity. Except for Miscanthus straw and rice husk produced at $550{ }^{\circ} \mathrm{C}$, all treatments were non-hydrophobic, which may have occurred because $550{ }^{\circ} \mathrm{C}$ is already a high temperature at which hydrophobic functional groups have largely been removed (Kinney et al., 2012). Further research should focus on relating physiochemical properties of different feedstock types and pyrolysis temperatures, such as surface area and residual ash content, to pure biochar hydraulic properties.

We found that biochar does not influence the hydraulic properties of a sandy soil. Only the saturated water content significantly increased compared to the control when amended with Miscanthus straw $550{ }^{\circ} \mathrm{C}$, rice husk $700{ }^{\circ} \mathrm{C}$ or wheat straw $700{ }^{\circ} \mathrm{C}$ biochar. The absence of an effect of biochar on soil hydraulic properties and of differences between the treatments is likely due to the low but realistic application rate of $10 \mathrm{tha}^{-1}$. Although this study is limited to one soil type and application rate, its results illustrate that biochar may not have the desired effects of enhancing soil hydraulic properties. This is important to better contextualize the expectations about biochar amendment as a strategy to improve agricultural soils.

\section{Declaration of Competing Interest}

The authors declare that they have no known competing financial interests or personal relationships that could have appeared to influence the work reported in this paper.

\section{Acknowledgements}

We thank Henny Gertsen for performing part of the water retention experiments, Harm Gooren for assistance in the lab experiments and Gerard Derks for assistance in setting up the field experiments. We thank Saran Sohi and Ondřej Mašek of the UK Biochar Research Centre for discussion and access to the Charchives.

Appendix 1 Bulk density $\left(\mathrm{g} \mathrm{cm}^{-3}\right)$ of crushed pure biochar samples, used to measure water retention characteristics, per feedstock type and pyrolysis temperature $\left(550\right.$ and $\left.700{ }^{\circ} \mathrm{C}\right)$. Values are averages $(n=5) \pm$ one standard deviation.

\begin{tabular}{llc} 
Feedstock type & Pyrolysis temperature & $700^{\circ} \mathrm{C}$ \\
\cline { 2 - 3 } & $550^{\circ} \mathrm{C}$ & $0.360 \pm 0.006$ \\
\hline Miscanthus straw pellets (MSP) & $0.353 \pm 0.010$ & $0.338 \pm 0.006$ \\
Oil seed rape (OSR) & $0.321 \pm 0.010$ & $0.175 \pm 0.006$ \\
Rice husk (RH) & $0.221 \pm 0.005$ & $0.470 \pm 0.005$ \\
Sewage sludge (SS) & $0.535 \pm 0.006$ & $0.353 \pm 0.008$ \\
Soft wood pellets (SWP) & $0.480 \pm 0.013$ & $0.435 \pm 0.019$ \\
Wheat straw pellets (WSP) & $0.316 \pm 0.007$ &
\end{tabular}

\section{Appendix A. Supplementary data}

Supplementary data to this article can be found online at https://doi.org/10.1016/j.geoderma.2020.114209.

\section{References}

Abel, S., Peters, A., Trinks, S., Schonsky, H., Facklam, M., Wessolek, G., 2013. Impact of biochar and hydrochar addition on water retention and water repellency of sandy soil. Geoderma 202-203, 183-191. https://doi.org/10.1016/j.geoderma.2013.03. 003.

Asai, H., Samson, B.K., Stephan, H.M., Songyikhangsuthor, K., Homma, K., Kiyono, Y., Inoue, Y., Shiraiwa, T., Horie, T., 2009. Biochar amendment techniques for upland rice production in Northern Laos. 1. Soil physical properties, leaf SPAD and grain yield. F. Crop. Res. 111, 81-84. https://doi.org/10.1016/j.fcr.2008.10.008.

Atkinson, C.J., Fitzgerald, J.D., Hipps, N.A., 2010. Potential mechanisms for achieving agricultural benefits from biochar application to temperate soils: A review. Plant Soil 337, 1-18. https://doi.org/10.1007/s11104-010-0464-5.

Barnes, R.T., Gallagher, M.E., Masiello, C.A., Liu, Z., Dugan, B., 2014. Biochar-induced changes in soil hydraulic conductivity and dissolved nutrient fluxes constrained by laboratory experiments. PLoS One 9. https://doi.org/10.1371/journal.pone. 0108340 .

Baronti, S., Vaccari, F.P., Miglietta, F., Calzolari, C., Lugato, E., Orlandini, S., Pini, R.,
Zulian, C., Genesio, L., 2014. Impact of biochar application on plant water relations in Vitis vinifera (L.). Eur. J. Agron. 53, 38-44. https://doi.org/10.1016/j.eja.2013. 11.003.

Bayabil, H.K., Stoof, C.R., Lehmann, J.C., Yitaferu, B., Steenhuis, T.S., 2015. Assessing the potential of biochar and charcoal to improve soil hydraulic properties in the humid Ethiopian Highlands: The Anjeni watershed. Geoderma 243-244, 115-123. https:// doi.org/10.1016/j.geoderma.2014.12.015.

Brodowski, S., John, B., Flessa, H., Amelung, W., 2006. Aggregate-occluded black carbon in soil. Eur. J. Soil Sci. 57, 539-546.

Cantrell, K.B., Hunt, P.G., Uchimiya, M., Novak, J.M., Ro, K.S., 2012. Impact of pyrolysis temperature and manure source on physicochemical characteristics of biochar. Bioresour. Technol. 107, 419-428. https://doi.org/10.1016/j.biortech.2011.11.084.

Cely, P., Gascó, G., Paz-Ferreiro, J., Méndez, A., 2015. Agronomic properties of biochars from different manure wastes. J. Anal. Appl. Pyrolysis 111, 173-182. https://doi.org/ 10.1016/j.jaap.2014.11.014.

Chintala, R., Schumacher, T.E., Kumar, S., Malo, D.D., Rice, J.A., Bleakley, B., Chilom, G., Clay, D.E., Julson, J.L., Papiernik, S.K., Gu, Z.R., 2014. Molecular characterization of biochars and their influence on microbiological properties of soil. J. Hazard. Mater. 279, 244-256. https://doi.org/10.1016/j.jhazmat.2014.06.074. 
Crombie, K., Mašek, O., Sohi, S.P., Brownsort, P., Cross, A., 2013. The effect of pyrolysis conditions on biochar stability as determined by three methods. Gcb Bioenergy 5, 122-131.

De Bakker, H., Schelling, J., Brus, D.J., Van Wallenburg, C., 1989. Systeem van bodemclassificatie voor Nederland: de hogere niveaus. Grondboor \& Hamer 20 (5) 229-229.

De Melo Carvalho, M.T., De Holanda Nunes Maia, A., Madari, B.E., Bastiaans, L., Van Oort, P.A.J., Heinemann, A.B., Da Silva, M.A.S., Petter, F.A., Marimon, B.H., Meinke, H., 2014. Biochar increases plant-available water in a sandy loam soil under an aerobic rice crop system. Solid Earth 5, 939-952. https://doi.org/10.5194/se-5-9392014.

DeBano, L.F., 2000. The role of fire and soil heating on water repellency in wildland environments: a review. J. Hydrol. 231-232, 195-206.

Dekker, L.W., Jungerius, P.D., 1990. Water repellency in the dunes with special reference to The Netherlands. Catena Suppl. 18, 173-183.

Dexter, A.R., 1988. Advances in characterization of soil structure. Soil Tillage Res. 11, 199-238.

Doerr, S.H., Shakesby, R.A., Walsh, R.P.D., 2000. Soil water repellency: Its causes, characteristics and hydro-geomorphological significance. Earth Sci. Rev. 51, 33-65. https://doi.org/10.1016/S0012-8252(00)00011-8.

Dokoohaki, H., Miguez, F.E., Laird, D., Horton, R., Basso, A.S., 2017. Assessing the Biochar Effects on Selected Physical Properties of a Sandy Soil: An Analytical Approach. Commun. Soil Sci. Plant Anal. 48, 1387-1398. https://doi.org/10.1080/ 00103624.2017.1358742.

Downie, A., Crosky, A., Munroe, P., 2009. Physical properties of biochar. In: Lehmann, J., Joseph, S. (Eds.), Biochar for Environmental Management: Science, Technology and Implementation. Earthscan, Washington DC, pp. 13-32.

Eibisch, N., Durner, W., Bechtold, M., Fub, R., Mikutta, R., Woche, S.K., Helfrich, M., 2015. Does water repellency of pyrochars and hydrochars counter their positive effects on soil hydraulic properties? Geoderma 245-246, 31-39. https://doi.org/10. 1016/j.geoderma.2015.01.009.

Esmaeelnejad, L., Shorafa, M., Gorji, M., Hosseini, S.M., 2016. Enhancement of physical and hydrological properties of a sandy loam soil via application of different biochar particle sizes during incubation period. Spanish J. Agric. Res. 14. https://doi.org/10. 5424/sjar/2016142-9190.

Agro, Eurofins, 2013. Bemestings Wijzer BLGG AgroXpertus Akker-/tuinbouw haaf west. Wageningen, Eurofins Nederland.

Gail, M.H., Green, S.B., 1976. A generalization of the one-sided two-sample KolmogorovSmirnov statistic for evaluating diagnostic tests. Biometrics 561-570.

Githinji, L., 2014. Effect of biochar application rate on soil physical and hydraulic properties of a sandy loam. Arch. Agron. Soil Sci. 60, 457-470. https://doi.org/10. 1080/03650340.2013.821698.

Głąb, T., Palmowska, J., Zaleski, T., Gondek, K., 2016. Effect of biochar application on soil hydrological properties and physical quality of sandy soil. Geoderma 281, 11-20. https://doi.org/10.1016/j.geoderma.2016.06.028.

Gray, M., Johnson, M.G., Dragila, M.I., Kleber, M., 2014. Water uptake in biochars: The roles of porosity and hydrophobicity. Biomass Bioenergy 61, 196-205. https://doi. org/10.1016/j.biombioe.2013.12.010.

Hale, L., Luth, M., Crowley, D., 2015. Biochar characteristics relate to its utility as an alternative soil inoculum carrier to peat and vermiculite. Soil Biol. Biochem. 81, 228-235. https://doi.org/10.1016/j.soilbio.2014.11.023.

Hardie, M., Clothier, B., Bound, S., Oliver, G., Close, D., 2014. Does biochar influence soil physical properties and soil water availability? Plant Soil 376, 347-361. https://doi. org/10.1007/s11104-013-1980-x.

Herath, H.M.S.K., Camps-Arbestain, M., Hedley, M., 2013. Effect of biochar on soil physical properties in two contrasting soils: an Alfisol and an Andisol. Geoderma 209-210, 188-197. https://doi.org/10.1016/j.geoderma.2013.06.016.

IUSS Working Group WRB. 2015. World Reference Base for Soil Resources 2014, update 2015 International soil classification system for naming soils and creating legends for soil maps. World Soil Resources Reports No. 106. FAO, Rome.

Jarvis, N., Etana, A., Stagnitti, F., 2008. Water repellency, near-saturated infiltration and preferential solute transport in a macroporous clay soil. Geoderma 143, 223-230. https://doi.org/10.1016/j.geoderma.2007.11.015.

Jeffery, S., Meinders, M.B.J., Stoof, C.R., Bezemer, T.M., van de Voorde, T.F.J., Mommer, L., van Groenigen, J.W., 2015. Biochar application does not improve the soil hydrological function of a sandy soil. Geoderma 251-252, 47-54. https://doi.org/10. 1016/j.geoderma.2015.03.022.

Jeong, C.Y., Dodla, S.K., Wang, J.J., 2016. Fundamental and molecular composition characteristics of biochars produced from sugarcane and rice crop residues and byproducts. Chemosphere 142, 4-13. https://doi.org/10.1016/j.chemosphere.2015.05. 084.

Joseph, S., Anh, M.L., Clare, A., Shackley, S., 2015. Socio-economic feasibility, implementation and evaluation of small-scale biochar projects. In: Biochar for environmental management: science, technology and implementation. London, England, Earthscan, pp. 851-877.

Kinney, T.J., Masiello, C.A., Dugan, B., Hockaday, W.C., Dean, M.R., Zygourakis, K.,
Barnes, R.T., 2012. Hydrologic properties of biochars produced at different temperatures. Biomass and Bioenergy 41, 34-43.

Laghari, M., Naidu, R., Xiao, B., Hu, Z., Mirjat, S., Hu, M., Kandhro, N., Chen, Z., Guo, D., Jogi, Q., Abudi, N., Fazal, S., 2016b. Recent developments in biochar as an effective tool for agricultural soil management: a review. J. Sci. Food Agric. 96, 4840-4849. https://doi.org/10.1002/jsfa.7753.

Lehmann, J., Joseph, S., 2009. Biochar for environmental management: science and technology. Earthscan, London, GB.

Lei, O., Zhang, R., 2013. Effects of biochars derived from different feedstocks and pyrolysis temperatures on soil physical and hydraulic properties. J. Soils Sediments 13, 1561-1572. https://doi.org/10.1007/s11368-013-0738-7.

Liu, Z., Dugan, B., Masiello, C.A., Barnes, R.T., Gallagher, M.E., Gonnermann, H., 2016. Impacts of biochar concentration and particles size on hydraulic conductivity and DOC leaching of biochar-sand mixtures. J. Hydrol. 533, 461-472.

Madari, B.E., Silva, M.A.S., Carvalho, M.T.M., Maia, A.H.N., Petter, F.A., Santos, J.L.S., Tsai, S.M., Leal, W.G.O., Zeviani, W.M., 2017. Properties of a sandy clay loam Haplic Ferralsol and soybean grain yield in a five-year field trial as affected by biochar amendment. Geoderma 305, 100-112. https://doi.org/10.1016/j.geoderma.2017. 05.029.

Major, J., Rondon, M., Molina, D., Riha, S.J., Lehmann, J., 2012. Nutrient leaching in a Colombian Savanna Oxisol amended with biochar. J. Environ. Qual. 41, 1076. https://doi.org/10.2134/jeq2011.0128.

Mann, H.B., Whitney, D.R., 1947. On a test of whether one of two random variables is stochastically larger than the other. Ann. Math. Stat. 50-60.

METER Group Inc., 2018. Mini Disk Infiltrometer: Manual.

Mollinedo, J., Schumacher, T.E., Chintala, R., 2015. Influence of feedstocks and pyrolysis on biochar's capacity to modify soil water retention characteristics. J. Anal. Appl. Pyrolysis 114, 100-108. https://doi.org/10.1016/j.jaap.2015.05.006.

Nelissen, V., Ruysschaert, G., Manka'Abusi, D., D’Hose, T., De Beuf, K., Al-Barri, B., Cornelis, W., Boeckx, P., 2015. Impact of a woody biochar on properties of a sandy loam soil and spring barley during a two-year field experiment. Eur. J. Agron. 62 , 65-78. https://doi.org/10.1016/j.eja.2014.09.006.

Novak, J.M., Busscher, W.J., Watts, D.W., Amonette, J.E., Ippolito, J.A., Lima, I.M., Gaskin, J., Das, K.C., Steiner, C., Ahmedna, M., Rehrah, D., Schomberg, H., 2012. Biochars impact on soil-moisture storage in an ultisol and two aridisols. Soil Sci. 177, 310-320. https://doi.org/10.1097/SS.0b013e31824e5593.

Ojeda, G., Mattana, S., Àvila, A., Maria, J., Volkmann, M., Bachmann, J., 2015. Are soil water functions affected by biochar application? Geoderma 249-250, 1-11.

Omondi, M.O., Xia, X., Nahayo, A., Liu, X., Korai, P.K., Pan, G., 2016. Quantification of biochar effects on soil hydrological properties using meta-analysis of literature data Geoderma 274, 28-34. https://doi.org/10.1016/j.geoderma.2016.03.029.

R Core Team (2013). R: A language and environment for statistical computing. $\mathrm{R}$ Foundation for Statistical Computing, Vienna, Austria. URL http://www.R-project. org/.

Rutherford, D.W., Wershaw, R.L., Rostad, C.E., Kelly, C.N., 2012. Effect of formation conditions on biochars: compositional and structural properties of cellulose, lignin, and pine biochars. Biomass Bioenergy 46, 693-701. https://doi.org/10.1016/j. biombioe.2012.06.026.

Schwen, A., Zimmermann, M., Leitner, S., Woche, S.K., 2015. Soil water repellency and its impact on hydraulic characteristics in a beech forest under simulated climate change. Vadose Zo. J. 14. https://doi.org/10.2136/vzj2015.06.0089.

Sorrenti, G., Masiello, C.A., Dugan, B., Toselli, M., 2016. Biochar physico-chemical properties as affected by environmental exposure. Sci. Total Environ. 563-564, 237-246. https://doi.org/10.1016/j.scitotenv.2016.03.245.

Steenhuis, T.S., Hunt, A.G., Parlange, J.Y., Ewing, R.P., 2005. Assessment of the application of percolation theory to a water repellent soil. Aust. J. Soil Res. 43, 357-360. https://doi.org/10.1071/SR04093.

Stiboka, 1975. Bodemkaart van Nederland. Wageningen, The Netherlands.

Suliman, W., Harsh, J.B., Abu-Lail, N.I., Fortuna, A.M., Dallmeyer, I., Garcia-Pérez, M., 2017. The role of biochar porosity and surface functionality in augmenting hydrologic properties of a sandy soil. Sci. Total Environ. 574, 139-147. https://doi.org/10. 1016/j.scitotenv. 2016.09.025.

UK Biochar Research Centre. (accessed December 2019).

Verheijen, F., Jeffery, S., Bastos, a C., Van Der Velde, M., Diafas, I., 2010. Biochar application to soils: a critical review of effects on soil properties, processes and functions, JRC Scientific and technical Report. https://doi.org/10.2788/472.

Yargicoglu, E.N., Yamini, B., Reddy, K.R., Spokas, K., 2015. Physical and chemical characterization of waste wood derived biochars. Waste Manag. 36, 256-268. https://doi.org/10.1016/j.wasman.2014.10.029.

Zimmerman, A.R., 2010. Abiotic and microbial oxidation of laboratory-produced black carbon (biochar). Environ. Sci. Technol. 44, 1295-1303.

Zornoza, R., Acosta, J.A., Muñoz, M.A., Faz, A., 2016. Chemosphere Stability, nutrien availability and hydrophobicity of biochars derived from manure, crop residues, and municipal solid waste for their use as soil amendments. Chemosphere 144, 122-130. https://doi.org/10.1016/j.chemosphere.2015.08.046. 